\title{
Prostaglandin output from the early pregnant rat uterus superfused in vitro, and the effect of A23187 and trifluoperazine
}

\author{
N. L. Poyser \\ Department of Pharmacology, University of Edinburgh Medical School, 1 George Square, \\ Edinburgh EH8 9JZ, U.K.
}

\begin{abstract}
Summary. The outputs of prostaglandin (PG) E-2 and 6-oxo-PGF-1 $\alpha$ from the early pregnant rat uterus superfused in vitro were significantly higher $(P<0.05)$ on Day 4 $(09: 00-10: 00 \mathrm{~h})$ and Day $5(14: 00-15: 00 \mathrm{~h})$ than on Day $2(09: 00-10: 00 \mathrm{~h})$ and Day 5 (14:00-15:00 h). PGF-2 $\alpha$ output was significantly higher $(P<0.05)$ only on Day 5 $(09: 00-10: 00 \mathrm{~h})$. PGE-2 was the major PG released at all times, although the amounts of PGF-2 $\alpha$ and/or 6-oxo-PGF-1 $\alpha$ released were often only slightly less. These findings are consistent with uterine $\mathrm{PGs}$ having a role in implantation in the rat.

A23187 stimulated 6-oxo-PGF-1 $\alpha$ output and, except on Day 4 (09:00-10:00 h), PGF- $2 \alpha$ output at all times studied. A23187 had little effect on PGE-2 output. The greatest stimulatory effect of A23187 on 6-oxo-PGF-1 $\alpha$ and PGF-2 $\alpha$ outputs occurred on Day 5 (09:00-10:00 h), which is the day of highest uterine PGH-2 synthetase activity. These increases in response to A23187 were prevented by trifluoperazine $(100 \mu \mathrm{M})$, a calmodulin antagonist. Trifluoperazine had no inhibitory effect on the high basal output of PGs on Day $5(09: 00-10: 00 \mathrm{~h})$, but caused a small increase in uterine PG output.
\end{abstract}

\section{Introduction}

There is much evidence that increased prostaglandin (PG) production by the uterus is necessary for implantation (on Day 5) in the rat (see Kennedy \& Armstrong, 1981). The concentrations of PGE-2, PGF-2 $\alpha$ and 6-oxo-PGF-1 $\alpha$ (which reflects PGI-2 production) are higher at the implantation sites than in the surrounding areas (Kennedy, 1977; Kennedy \& Zamecnik, 1978), and indomethacin treatment delays or prevents implantation in the rat (Kennedy, 1977; Phillips \& Poyser, 1981). There is little information on the output of PGs from the early pregnant rat uterus, except for one study which reported that the PGF- $2 \alpha$ concentration, but not the PGE-2 concentration, in the uterine venous plasma was increased on Day 5 (Shaikh, Naqvi \& Saksena, 1977). The PGI-2 concentration was not measured. Consequently, the outputs of PGs from the early pregnant rat uterus superfused in vitro have been measured. Such an in-vitro technique avoids contamination by 'blood products' and has previously been shown to monitor accurately PG release in vivo from the guinea-pig uterus (Poyser \& Brydon, 1983). The effects of A23187 (a calcium ionophore) and trifluoperazine (a calmodulin antagonist) of uterine PG release have been studied to investigate some of the possible intracellular processes controlling PG synthesis in the rat uterus.

\section{Materials and Methods}

Twenty-four Wistar rats weighing 200-250 g were housed under controlled lighting conditions (lights on 06:00-20:00 h). Vaginal smears were taken daily and examined microscopically. Oestrus 
was defined as the day of maximum cornification preceding the day of leucocytic infiltration. All rats had shown at least 2 consecutive 4-day cycles before being placed with a male rat on the day of pro-oestrus. Successful mating was confirmed the following morning (Day 1 of pregnancy) by the presence of spermatozoa in the vagina and the subsequent increase in plasma progesterone concentration.

Six rats were killed, by stunning and incising the neck, between 09:00 and 10:00 h (a.m.) on each of Days 2, 4 and 5 of pregnancy, and between 14:00 and 15:00 h (p.m.) on Day 5 of pregnancy. A blood sample was collected into a heparinized $(20 \mathrm{U} / \mathrm{ml})$ syringe from the incised neck of each rat. The blood was centrifuged at $2500 \mathrm{~g}$, and the plasma was withdrawn and stored at $-20^{\circ} \mathrm{C}$ before being assayed for progesterone as described previously (Poyser \& Horton, 1975; Fenwick, Jones, Naylor, Poyser \& Wilson, 1977; Poyser, 1984a). All the samples were measured in 2 assays.

The uterus from each rat was removed, and the two uterine horns were separated, blotted dry and weighed. Each uterine horn was 'opened' by cutting longitudinally and was suspended in an organ bath attached to an isotonic lever under a load of $1 \mathrm{~g}$. The uterine horns were superfused (5 $\mathrm{ml} / \mathrm{min}$ ) with Krebs' solution (for composition see Mitchell, Poyser \& Wilson, 1977) at $37^{\circ} \mathrm{C}$ and pre-gassed with $5 \% \mathrm{CO}_{2}$ and $95 \% \mathrm{O}_{2}$. After an initial settling period of $60 \mathrm{~min}$ for all uterine horns, samples of superfusate were collected for 10-min periods consecutively over the next 90 min (i.e. 9 samples) from the uterine horns of rats killed between 09:00 and 10:00 h on Days 2 and 4, and between 14:00 and 15:00 h on Day 5. A23187 $(1 \mu \mathrm{g} / \mathrm{ml}$; Sigma Chemical Co. Ltd, Poole, U.K.) was added to the Krebs' solution during the collection of Samples 4, 5 and 6 from one uterine horn of each of these rats. Samples of superfusate were collected for $10-\mathrm{min}$ periods consecutively for 100 min (i.e. 10 samples) from the uterine horns of rats killed between 09:00 and 10:00 h on Day 5 . Trifluoperazine (100 $\mu \mathrm{M}$; Smith, Kline and French Labs. Ltd, Welwyn Garden City, U.K.) was added to the Krebs' solution during the collection of Samples 4-7 from one uterine horn of each rat, and A23187 $(1 \mu \mathrm{g} / \mathrm{ml})$ was added to the Krebs' solution during the collection of Samples 6 and 7 from both uterine horns.

After collection, PGs were extracted and stored and the amounts of PGF-2 $\alpha$, PGE-2 and 6-oxoPGF- $1 \alpha$ present in the samples were measured by radioimmunoassay as described previously (Poyser, 1984a). The intra-assay coefficients of variation, calculated from the variation between the duplicate results obtained, were $9.8 \%$ (PGF-2 $\alpha$ ), 10.4\% (PGE-2) and 10.7\% (6-oxo-PGF- $1 \alpha$ ). The inter-assay coefficients of variation, calculated from the results obtained by incorporating a known amount of the appropriate PG into each assay, were 9.5\% (PGF-2 $\alpha$ ), 10.3\% (PGE-2) and $11.5 \%$ (6-oxo-PGF-1 $\alpha$ ).

Statistical tests. Changes in output of a particular PG with time were analysed by Duncan's multiple range test. However, if the variances of the groups were unequal by the variance $F$ ratio test, comparisons were made using a modified $t$ test for unequal variances. All other comparisons were made using Student's $t$ test. All results are expressed as the mean ( \pm s.e.m., $n=6$ ).

\section{Results}

The mean average outputs of PGF- $2 \alpha$, PGE-2 and 6-oxo-PGF- $1 \alpha$ during the first 50 min of sample collection from one uterine horn of the rats studied are shown in Table 1. PGE-2 was released in the greatest amounts on each day, although the outputs of PGF- $2 \alpha$ and/or 6-oxo-PGF- $1 \alpha$ were often only slightly lower. The outputs of PGE-2 and 6-oxo-PGF-1 $\alpha$ were significantly higher $(P<0.05)$ on Day 4 (a.m.) and Day 5 (a.m.) than on Day 2 (a.m.) and Day 5 (p.m.). The output of PGF-2 $\alpha$ was significantly increased $(P<0.05)$ on Day 5 (a.m.). Plasma progesterone concentrations typically increased between Days 2 and 4, and then remained high with some fluctuation (Table 1).

A23187 significantly increased $(P<0.05)$ PGF- $2 \alpha$ output on Day 2 (a.m.), Day 5 (a.m.) and Day 5 (p.m.) (Text-figs 1a, 2a \& 1c), but not on Day 4 (a.m.) (Text-fig. 1b). A23187 significantly increased 6-oxo-PGF-1 $\alpha$ output at all times studied (Text-figs 1a, b, c; Text-fig. 2a), although the 


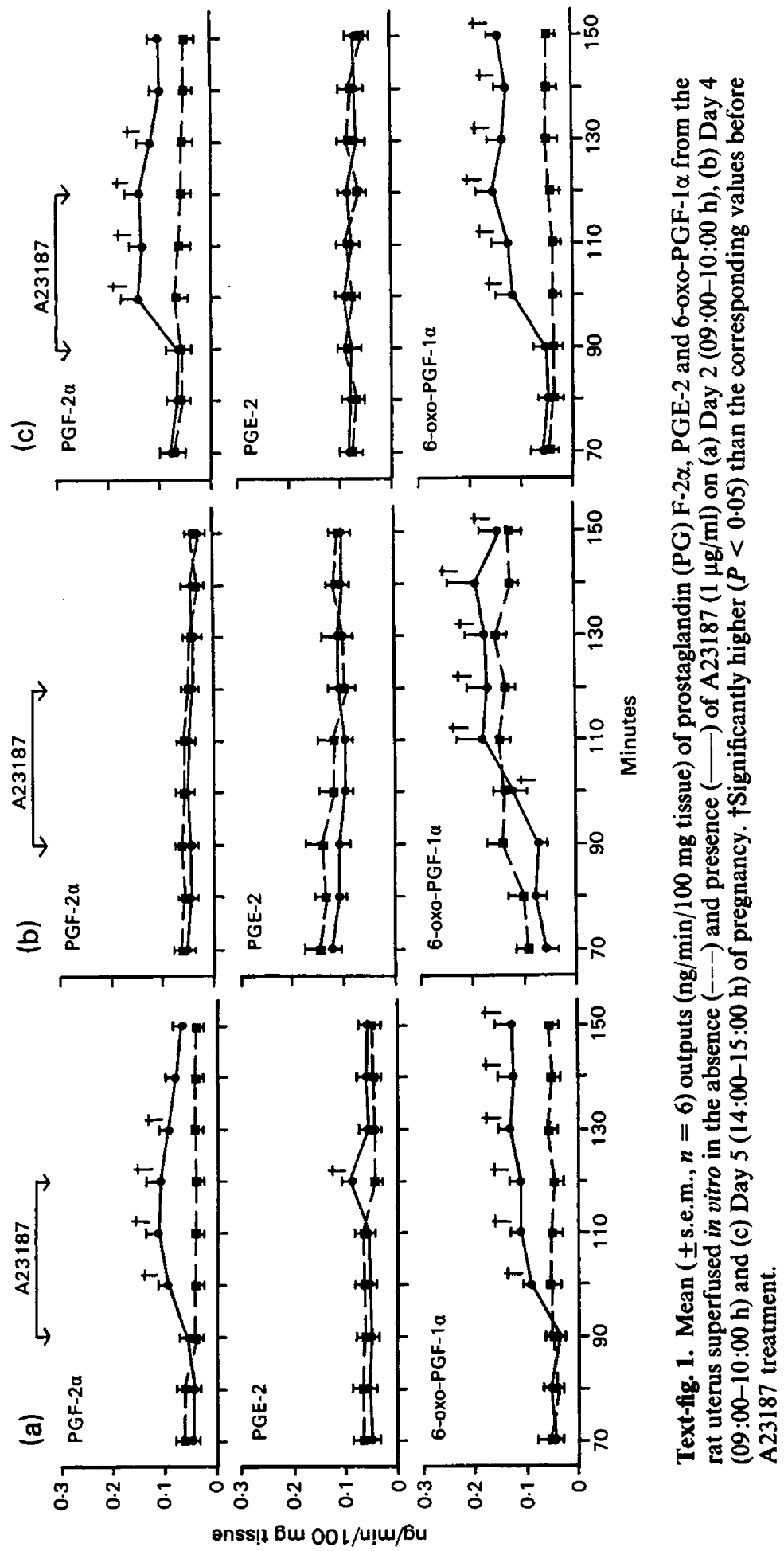


Table 1. Mean ( \pm s.e.m., $n=6$ ) average outputs (ng/min/100 mg tissue) of prostaglandin (PG) F- $2 \alpha$, PGE-2 and 6-oxo-PGF-1 $\alpha$ from the uterus superfused in vitro and plasma progesterone concentrations $(\mathrm{ng} / \mathrm{ml})$ during early pregnancy in the rat.

\begin{tabular}{lcccc}
\hline & \multicolumn{4}{c}{ Day of pregnancy } \\
\cline { 2 - 5 } \cline { 3 - 5 } & $2(09: 00-10: 00 \mathrm{~h})$ & $4(09: 00-10: 00 \mathrm{~h})$ & $5(09: 00-10: 00 \mathrm{~h})$ & $5(14: 00-15: 00 \mathrm{~h})$ \\
\hline PG output & & & & \\
PGF-2 $\alpha$ & $0.051 \pm 0.007^{\mathrm{a}}$ & $0.059 \pm 0.005^{\mathrm{a}}$ & $0.108 \pm 0.009^{\mathrm{b}}$ & $0.066 \pm 0.011^{\mathrm{a}}$ \\
PGE-2 & $0.061 \pm 0.005^{\mathrm{a}}$ & $0.131 \pm 0.019^{\mathrm{b}}$ & $0.130 \pm 0.015^{\mathrm{b}}$ & $0.077 \pm 0.010^{\mathrm{a}}$ \\
6-oxo-PGF-1 $\alpha$ & $0.052 \pm 0.011^{\mathrm{a}}$ & $0.125 \pm 0.015^{\mathrm{b}}$ & $0.089 \pm 0.008^{\mathrm{b}}$ & $0.039 \pm 0.066^{\mathrm{a}}$ \\
\hline Plasma progesterone & $19.9 \pm 2.8^{1}$ & $69.0 \pm 3.4^{2}$ & $59 \cdot 7 \pm 2 \cdot 1^{3}$ & $76 \cdot 6 \pm 9 \cdot 1^{2.3}$ \\
\hline
\end{tabular}

In any one horizontal line, values with the same superscript are not significantly different $(P>0.05)$.
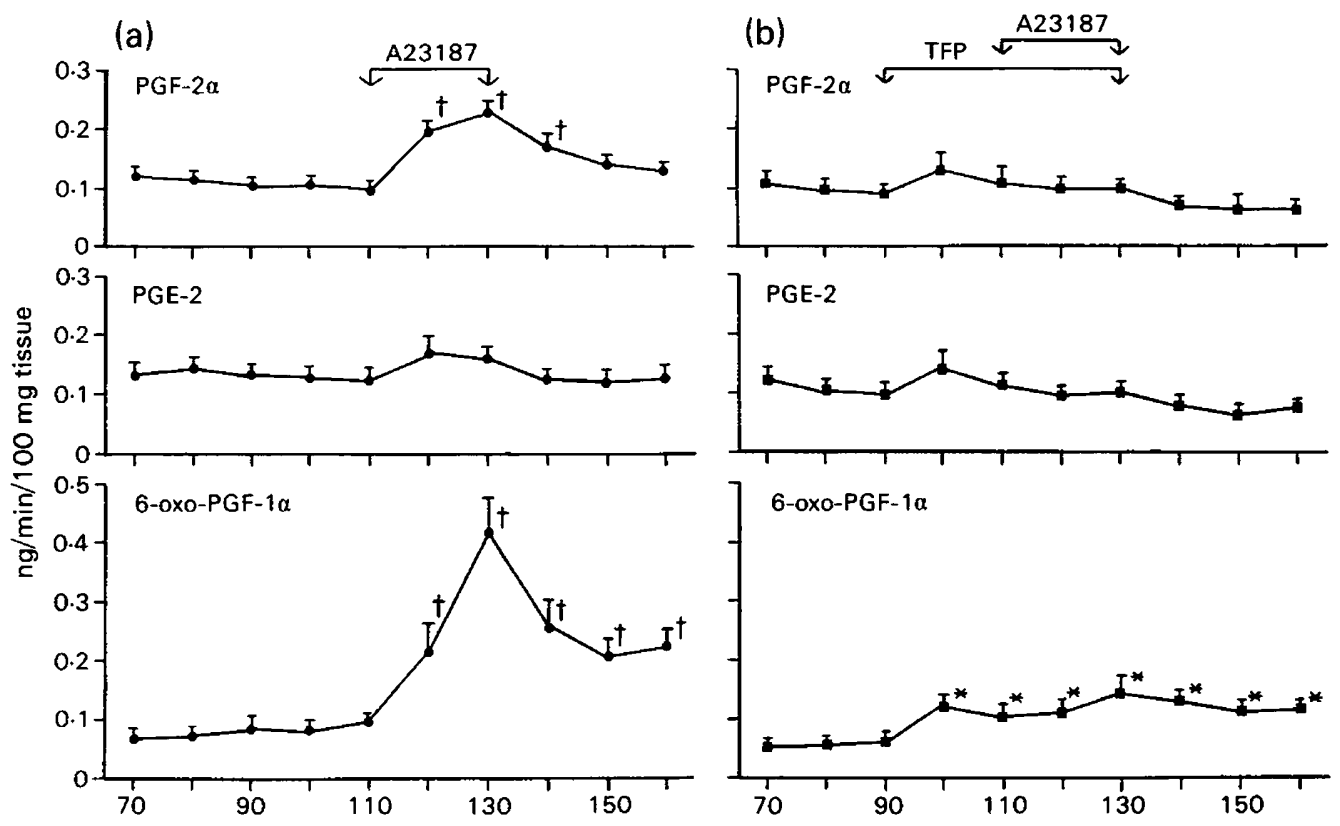

Text-fig. 2. Effect of trifluoperazine (TFP; $100 \mu \mathrm{M}$ ) on (a) basal and (b) A23187-stimulated mean ( \pm s.e.m., $n=6$ ) outputs of prostaglandin (PG) F- $2 \alpha$, PGE-2 and 6-oxo-PGF-1 $\alpha$ from the rat uterus superfused in vitro on Day $5(09: 00-10: 00 \mathrm{~h})$ of pregnancy. $†$ Significantly higher $(P<$ $0.05)$ than the corresponding values before A23187 treatment. *Significantly higher $(P<0.05)$ than the corresponding values before trifluoperazine treatment.

increase on Day 4 (a.m.) was not clear-cut since the basal (control) output tended to fluctuate and increase over the period of sample collection (Text-fig. 1b). A23187 had no effect on PGE-2 output except for a small, significant increase $(P<0.05)$ on Day 2 (a.m.) (Text-fig. 1a). The maximum outputs of PGF- $2 \alpha$ and 6-oxo-PGF- $1 \alpha$ induced by A23187 on Day 5 (a.m.) were significantly higher $(P<0 \cdot 05)$ than those induced on Day 2 (a.m.), Day 4 (a.m.) and Day 5 (p.m.). A23187 had no effect on the contractile state of the uterine horns.

Trifluoperazine $(100 \mu \mathrm{M})$ caused a small increase in uterine PG output which was significant $(P<0.05)$ for 6-oxo-PGF-1 $\alpha$. However, trifluoperazine $(100 \mu \mathrm{M})$ prevented the increase in outputs of PGF- $2 \alpha$ and 6-oxo-PGF-1 $\alpha$ induced by A23187 on Day 5 (a.m.) (Text-fig. 2b). 


\section{Discussion}

Uterine PG output in the pregnant rat was increased for $24 \mathrm{~h}$ immediately before the presumed time of implantation. PGE-2 was the major PG produced, which is consistent with PGE-2 being the only PG capable of causing the increase in uterine capillary permeability associated with implantation (Kennedy, 1979a, b). PGE-2 binding sites are present in the pseudopregnant rat uterus in greater numbers on Day 5 than on Day 4 (Kennedy, Martel \& Psychoyos, 1983), suggesting that the uterus is more responsive to the increased PGE-2 production on Day 5 than on Day 4. PGE-2, PGF- $2 \alpha$ and PGI-2 will all induce decidualization of the rat uterus (Sananes, Baulieu \& Le Goascogne, 1981; Miller \& Morchoe, 1982a; Kennedy \& Lukash, 1982). The increased production of these PGs by the rat uterus on Days 4 and 5 is consistent with PGs having a role in the decidualization process, especially as decidualization of the rat uterus in response to an appropriate stimulus is prevented by indomethacin (Tobert, 1976; Sananes et al., 1981; Miller \& Morchoe, 1982b).

The increased output of PGF- $2 \alpha$ from the rat uterus on Day 5 (a.m.) in vitro is consistent with the in vivo findings of Shaikh et al. (1977). However, these authors failed to find an increase in uterine PGE-2 output on Days 4 and 5, and PGF- $2 \alpha$ output always greatly exceeded PGE-2 output. Differences in experimental design may be the reason for the inconsistencies between the two studies. Oestradiol acting on a progesterone-primed uterus is the optimal steroidal stimulus for increased PGF-2 $\alpha$ and PGE-2 secretion from the ovariectomized rat uterus in vivo, with maximum PG output occurring $12 \mathrm{~h}$ after the oestradiol injection (Castracane \& Jordan, 1976). The increased secretion of oestradiol by the ovary of the pregnant rat late on Day 3 and early on Day 4 (Watson, Anderson, Alam, O'Grady \& Heald, 1975) may be responsible for the increased production of PGs by the uterus on Day 4 (a.m.) and Day 5 (a.m.). However, PGF-2 $\alpha$ output was not increased on Day 4 (a.m.), and the increased PG output on Day 5 (a.m.) occurred considerably later than $12 \mathrm{~h}$ after the oestradiol surge. Furthermore, the treatment of ovariectomized rats with progesterone and oestradiol, in a regimen which allows implantation, failed to increase uterine PG output from the uterus superfused in vitro (Brown, Gosden \& Poyser, 1984). It appears that other factors, as well as or other than the ovarian steroid hormones, form the stimulus for increased uterine PG production on Days 4 and 5.

The activities of phospholipase A-2 (PLA-2; the enzyme that releases arachidonic acid from phospholipids) and PGH-2 synthetase (the enzyme which converts arachidonic acid into PGH-2) are greatest on Day 4 (a.m.) and Day 5 (a.m.), respectively (Cox, Cheng \& Dey, 1982; Phillips \& Poyser, 1981). These findings are consistent with the increased outputs of PGs on Days 4 (a.m.) and 5 (a.m.), although it would appear that the absolute activity of neither enzyme is solely responsible for controlling the amounts of PGs synthesized by the uterus since total PG production is increased to a similar extent on both days.

The calcium ionophore, A23187, stimulated PGF-2 $\alpha$ output, except on Day 4 (a.m.), and 6-oxoPGF-1 $\alpha$ output, but had little effect on PGE-2 output from the early pregnant rat uterus. Similar actions of A23187 have been reported for the non-pregnant and early pregnant guinea-pig uterus (Poyser \& Brydon, 1983; Poyser, 1984a), an effect which is dependent upon extracellular $\mathrm{Ca}^{2+}$ (Poyser, 1984b). A23187 has been reported to stimulate 6-oxo-PGF-1 $\alpha$ output from the myometrium, but not from the endometrium, of rat uteri superfused in vitro (Campos, Liggins \& Seamark, 1980). In the present study, it is not clear why A23187 failed to increase PGF- $2 \alpha$ output from the rat uterus on Day 4 (a.m.). In the study of Campos et al. (1980), A23187 had no effect on PGF- $2 \alpha$ release from the endometrium, the major site of PGF- $2 \alpha$ synthesis in the rat uterus (Williams, Sneddon \& Harney, 1974; Brown \& Poyser, 1985), and only had a small stimulatory effect on PGF- $2 \alpha$ release from the myometrium. These rats were ovariectomized and treated with oestradiol, so perhaps oestradiol had prevented the stimulatory action of A23187 on uterine PGF$2 \alpha$ output in some way. Consequently, the peak of oestradiol between Days 3 and 4 (Watson et al., 1975) may be responsible for the lack of effect of A23187 on PGF- $2 \alpha$ release on Day 4 (a.m.). The 
greatest output of PGF- $2 \alpha$ and 6-oxo-PGF-1 $\alpha$ from the uterus in response to A23187 occurred on Day 5 (a.m.). This suggests that PGH-2 synthetase activity (which is maximal on Day 5) and not PLA-2 activity (which is maximal on Day 4) determines the maximum amounts of PGs which can be synthesized by the uterus.

Trifluoperazine, a calmodulin antagonist, had no inhibitory effect on the high basal outputs of PGs from the uterus on Day 5 (a.m.) and, in fact, it had a small stimulatory action. Nevertheless, trifluoperazine prevented the increase in PG output normally induced by A23187. Similar actions of trifluoperazine $(100 \mu \mathrm{M})$ have been reported for the guinea-pig uterus (Poyser, 1985), for which trifluoperazine failed to prevent the conversion of arachidonic acid into PGs. The rat is therefore another species in which calmodulin is apparently involved in the process by which an increase in intracellular $\mathrm{Ca}^{2+}$ concentration activates PLA-2 to release arachidonic acid from phospholipids for PG synthesis in the uterus. Whether calcium and calmodulin are involved in the physiological response in vivo requires further study.

I thank Miss Isa Ramsay for technical help. Authentic PGs were kindly supplied by the Upjohn Company, Kalamazoo, Michigan, U.S.A.

\section{References}

Brown, C.G. \& Poyser, N.L. (1985) Further studies on prostaglandin and thromboxane production by the rat uterus during the oestrous cycle. J. Reprod. Fert. 73, 391-399.

Brown, C.G., Gosden, R.G. \& Poyser, N.L. (1984) Effects of age and steroid treatment on prostaglandin production by the rat uterus in relation to implantation. J. Reprod. Fert. 70, 649-656.

Campos, G.A., Liggins, G.C. \& Seamark, R.F. (1980) Differential production of PGF and 6-keto-PGF $2 \alpha$ by the rat endometrium and myometrium in response to oxytocin, catecholamines and calcium ionophore. Prostaglandins 20, 297-310.

Castracane, V.J. \& Jordan, V.C. (1976) Considerations into the mechanism of estrogen-stimulated uterine prostaglandin synthesis. Prostaglandins 12, 243-251.

Cox, C., Cheng, H.C. \& Dey, S.K. (1982) Phospholipase $\mathrm{A}_{2}$ activity in the rat uterus during early pregnancy. Prostaglandins, Leuk. \& Med. 8, 375-382.

Fenwick, L., Jones, R.L., Naylor, B., Poyser, N.L. \& Wilson, N.H. (1977) Production of prostaglandins by the pseudopregnant rat uterus, in vitro, and the effect of tamoxifen, with the identification of 6-ketoprostaglandin $\mathrm{F}_{1 \alpha}$ as a major product. Br. J. Pharmac. 59, 191-199.

Kennedy, T.G. (1977) Evidence for a role of prostaglandins in the initiation of blastocyst implantation in the rat. Biol. Reprod. 16, 286-291.

Kennedy, T.G. (1979a) Prostaglandins and increased endometrial vascular permeability resulting from the application of an artificial stimulus to the uterus of the rat sensitised for the decidual cell reaction. Biol. Reprod. 20, 560-566.

Kennedy, T.G. (1979b) Does prostaglandin $\mathrm{I}_{2}$ (PGI $)$ mediate the increased endometrial vascular permeability which results from the application of a deciduogenic stimulus to the sensitised rat uterus? Biol. Reprod. 20, Suppl. 1, 99A, Abstr.

Kennedy, T.G. \& Armstrong, D.T. (1981) The role of prostaglandins in endometrial vascular changes at implantation. In Cellular and Molecular Aspects of Implantation, pp. 349-363. Eds S. R. Glasser \& D. W. Bullock. Plenum Press, New York.

Kennedy, T.G. \& Lukash, L.A. (1982) Induction of decidualization in rats by the intrauterine infusion of prostaglandins. Biol. Reprod. 27, 253-260.

Kennedy, T.G. \& Zamecnik, J. (1978) Concentration of 6keto-prostaglandin $\mathrm{F}_{1 \alpha}$ is markedly elevated at site of blastocyst implantation in the rat. Prostaglandins 16, 599-605.

Kennedy, T.G., Martel, D. \& Psychoyos, A. (1983) Endometrial prostaglandin $\mathbf{E}_{2}$ binding: characterization in rats sensitized for the decidual cell reaction and changes during pseudopregnancy. Biol. Reprod. 29, 556-564.

Miller, M.M. \& Morchoe, C.C.C. (1982a) Decidual cell reaction induced by prostaglandin $\mathrm{F}_{2 \alpha}$ in the mature oophorectomized rat. Cell Tissue Res. 225, 189-199.

Miller, M.M. \& Morchoe, C.C.C. (1982b) Inhibition of artificially induced decidual cell reaction by indomethacin in the mature oophorectomized rat. Anat. Rec. 204, 223-230.

Mitchell, S., Poyser, N.L. \& Wilson, N.H. (1977) Effect of p-bromophenacyl bromide, an inhibitor of phospholipase $A_{2}$, on arachidonic acid release and prostaglandin synthesis by the guinea-pig uterus in vitro. Br. J. Pharmac. 59, 107-113.

Phillips, C.A. \& Poyser, N.L. (1981) Studies on the involvement of prostaglandins in implantation in the rat. J. Reprod. Fert. 62, 73-81.

Poyser, N.L. (1984a) Prostaglandin production by the early pregnant guinea-pig uterus in relation to implantation and luteal maintenance, and the effect of oestradiol. J. Reprod. Fert. 72, 117-127.

Poyser, N.L. (1984b) Effect of using calcium-free Krebs' solution on basal and A23187-stimulated prostaglandin output from the Day 15 guinea-pig uterus superfused in vitro. Prostaglandins, Leuk. \& Med. 13, 259-269.

Poyser, N.L. (1985) Effect of trifluoperazine, a calmodu- 
lin antagonist, on prostaglandin output from the guinea-pig uterus. J. Reprod. Fert. 73, 295-303.

Poyser, N.L. \& Brydon, L.J. (1983) Prostaglandin release from the guinea-pig uterus superfused in vitro. Effect of stage of estrous cycle, progesterone, estradiol, oxytocin and A23187. Prostaglandins 25, 443-456.

Poyser, N.L. \& Horton, E.W. (1975) Plasma progesterone levels in guinea-pigs actively immunised against prostaglandin $\mathrm{F}_{2 \alpha}$, hysterectomized or treated with intra-uterine indomethacin. J. Endocr. 67, 81-88.

Sananes, N., Baulieu, E.-E. \& Le Goascogne, C. (1981) A role for prostaglandins in decidualization of the rat uterus. J. Endocr. 89, 25-33.

Shaikh, A.A., Naqvi, R.H. \& Saksena, S.K. (1977) Prostaglandins $\mathrm{E}$ and $\mathrm{F}$ in uterine venous plasma in relation to peripheral plasma levels of progesterone and $20 \alpha$ hydroxyprogesterone in the rat throughout pregnancy and parturition. Prostaglandins 13, 311320.

Tobert, J.A. (1976) A study of the possible role of prostaglandins in decidualization using a nonsurgical method for the instillation of fluids into the rat uterine lumen. J. Reprod. Fert. 47, 391-393.

Watson, J., Anderson, F.B., Alam, M., O'Grady, J.E. \& Heald, P.J. (1975) Plasma hormones and pituitary luteinizing hormone in the rat during the early stages of pregnancy and after post-coital treatment with tamoxifen (ICI 46,474). J. Endocr. 65, 7-17.

Williams, K.I., Sneddon, J.M. \& Harney, P.J. (1974) Prostaglandin production by the pregnant rat uterus in vitro and its relevance to parturition. Pol. $J$. Pharmac. Pharm. 26, 207-215.

Received 5 October 1984 